\title{
LA CULTURA CLERICAL EN EL OBISPADO DE JAÉN EN LA BAJA EDAD MEDIA
}

\author{
POR
}

\author{
Manuela Garcfa Pardo \\ Universidad de Almería
}

\section{RESUMEN}

Este artículo pretende poner de manifiesto la mala preparación de los clérigos a causa de permitirse el acceso a beneficios vacantes a personas no preparadas y la existencia de numerosos clérigos que vivían en situaciones precarias.

\section{ABSTRACT}

The author intends to express the wrong formation of the clergymen because of was permitted the access to vacant benefits to clergymen without formation and the clergymen were living in precarious situations.

El nivel cultural de los clérigos se convierte en un punto de especial preocupación a partir de la Reforma Gregoriana, debido al convencimiento de que tan sólo a través de la elevación de dicho nivel cultural entre los miembros del clero, sería posible llevar a cabo y afianzar la tan ansiada reforma.

A pesar de esta premisa nuestro estudio se encuentra enmarcado en un ámbito nuevo, como el que supone la restauración de una diócesis, en un territorio que sirve de frontera con el mundo musulmán y en el que el elemento eclesiástico se va a ver influenciado por la realidad con la que coexiste.

A partir de la conquista de Baeza (1226) los designios eclesiásticos y espirituales del obispado se sitúan en la línea del arzobispado de Toledo en el cual se incluye.

$\mathrm{I}^{\text {er }}$ Congreso de Historia de la Iglesia Hispania Sacra 51 (1999) 
El nivel cultural de los clérigos en general fue un motivo de preocupación que quedó plasmado en el III y IV Concilio de Letrán. Sus directrices marcarán una coordenada que se verá reflejada, a partir de este momento, en los diferentes concilios y sínodos diocesanos en las más diversas zonas, llegando a ser valorados por diferentes historiadores, como es el caso de Guijarro González', como el punto de partida de la institución de las escuelas catedralicias en las diócesis hispanas, entre otras.

En la Península, y más concretamente en Castilla, esta normativa queda recogida en el concilio provincial de Valladolid (1228). En él la legislación conciliar se va a ver encaminada fundamentalmente hacia dos aspectos. Por una parte, se ordena que en cada iglesia catedral se escojan dos personas, de las más preparadas, para que sean las encargadas de la predicación y de oír las confesiones. Por otra, se establece que los beneficiados que no sepan latín sean privados de sus beneficios mientras que no lo aprendan, dándoles un plazo de tres años a los que quisieran asistir a la escuela y aprenderlo².

En este concilio se denuncia a los clérigos que no saben leer latín, pero las medidas por él adoptadas no tienen especial incidencia en la clerecía. Así, casi dos siglos después, en la diócesis de Jaén se sigue acusando la misma falta.

En la misma línea van a ir los cánones que se dictan en el concilio nacional de Valladolid de 1322.

El arzobispado de Toledo, a través de los concilios provinciales, intenta buscar una solución a esta falta, haciendo ver la necesidad de contar con clérigos que estuviesen suficientemente preparados y con un nivel cultural, por lo menos mínimo. Las medidas más serias se dictaron en el concilio provincial de Toledo celebrado en 1339, al que sabemos asistió el obispo de Jaén. Luego la información, la necesidad y la justificación de las medidas aquí predicadas le llegan de primera mano, sin intermediarios. En este concilio se van a recoger las medidas que fueron dadas con anterioridad en el concilio nacional de Valladolid de $1322^{3}$, insistiéndose en que no fuesen aceptados como clérigos aquellos que no supiesen explicarse por escrito, retomando la preocupación por la formación adecuada del clero, estipulándose que, en todas las catedrales y

I GUIJARRo GoNZÁLEZ, S., La transmisión social de la cultura en la Edad Media castellana (siglos XI-XV): Las escuelas y la formación del clero de las catedrales, T. I, Tesis doctoral inédita, Santander, 1992, p. 70.

2 BELTRÁN DE HEREDLA, V., «La formación intelectual del clero en España durante los siglos XII, XIII y XIV», Revista Española de Teología, Vol. VI, p. 335.

3 Así queda recogido por el profesor Sánchez Herrero en el estudio y edición que realiza de los concilios provinciales de Toledo celebrados entre los siglos XIV y XV. SÁNCHEZ HERRERO, J., Concilios provinciales y sínodos toledanos de los siglos XIV y XV. La religiosidad cristiana del clero y pueblo, La Laguna, 1976. 
colegiatas, por lo menos uno de cada diez prebendados fuese enviado a las universidades para obtener grados en Teología y Derecho Canónico. Caso de que los cabildos no cumpliesen con esta obligación, los obispos lo harían por su cuenta, ya que la norma era «nullus nisi litteratus, ad clericatum promoveatun»".

La diócesis de Jaén no constituye una excepción. Más al contrario, son numerosas las llamadas que se hacen a la necesidad de elevar el nivel cultural del clero. Especialmente se pone el acento en el clero catedralicio, en todos sus estratos, es decir, dignidades, canónigos, racioneros y beneficiados en general de la catedral. estos, como representantes de la máxima jerarquía eclesiástica en este obispado, tenían especial obligación de predicar con su ejemplo y cuidar su nivel cultural.

Ya veremos que a pesar de la idea bastante extendida, las llamadas al orden y a la necesidad de cubrir las expectativas culturales requeridas van a ser muy numerosas.

Se constituyen dos grandes líneas en torno a la cultura de los clérigos: mientras que parece que el peso de la enseñanza de los beneficiados de la catedral se deja recaer en manos del cabildo, en lo relativo al resto de los beneficiados de todo el obispado, el peso o la decisión acerca de ellos recae más sobre la figura del obispo o de su lugarteniente. Se establece que todos los beneficiados han de saber gramática y lengua latina, leer y cantar, puntualizándose además que ningún capellán podrá ser admitido para otorgarle las ordenes mayores ni servir cualquier beneficio sin que se tenga constancia de que sabe las tres cosas antes mencionadas ${ }^{5}$.

Esta obligación, que tal y como aparece en la nota a pie de página, hace referencia al sínodo de 1511, se establece como una respuesta al estatuto de la catedral, que recoge la idoneidad y suficiencia que habían de mostrar las dignidades, canónigos y racioneros de la iglesia de Jaén, cualidades que se debían de hacer extensivas al resto de la clerecía de la diócesis en la medida de lo posible, de manera que se llega a defender que todos aquellos beneficiados del obispado que tuviesen treinta años o más y no dominasen las tres cosas antes mencionadas, es decir, que no supiesen gramática ni lengua latina, leer y cantar canto llano, $o$ alguna de ellas, tendrían que hacerse servir por otros clérigos que sí dominaran las tres materias mencionadas, hasta el momento en que ellos mismos fuesen capaces de dominarlas correctamente. Lo normal es que, estas personas que se eligen para sustituir a estos clérigos ignorantes, sean capellanes que con anterioridad han tenido que demostrar al obispo o a su provisor

4 RIVERA RECIO, J. F., Los arzobispos de Toledo en la Baja Edad Media (siglos XII-XV), Toledo, 1969, pp. 86-87.

5 Sinodo de 1511. Archivo de la catedral de Jaén, Título II, fol. XVI r - XVI v. 
que realmente están preparados y son capaces de acometer las tareas que de ellos van a ser requeridas.

Si se trata de beneficiados que se encuentran situados en un arco de edad que iría entre los diez y treinta años, estarían obligados, pasados seis meses de la publicación de esta constitución, a acudir a la escuela y aprender los tres requisitos que le son exigidos, permaneciendo en esta actividad durante cuatro años, al cabo de los cuales han de presentarse delante del obispo o de su provisor, mostrándole cómo han aprendido y cómo se desenvuelven correctamente en sus conocimientos recién adquiridos.

Para que estos beneficiados se apliquen en su obligación, se establece que aquel que pasados los cuatro años siga sin saber latín ni leer ni cantar debe pagar como pena la cuarta parte de los frutos y rentas de sus beneficios correspondientes a un año, hasta que alcance la situación deseada. La cuantía de esta pena se dedicaba a la fabrica de la iglesia de la que el infractor fuese beneficiado.

Esta obligación se hace extensiva no sólo a los que gozasen ya de un beneficio, sino también a los que accedían a él, aunque es curioso que no supusiese un impedimento el no gozar de esta instrucción, pues se ve claramente, que no por ello se impedía que se consiguiera el beneficio, sino que tan sólo se obligaba, una vez conseguido, a que la persona que no gozase de estos conocimientos intelectuales se sometiese inmediatamente a su aprendizaje.

El mismo deber se hacía extensivo a todos aquellos clérigos que tenían beneficio servidero, así como a los capellanes perpetuos.

A pesar de todos los esfuerzos, en la documentación se van dejando pistas que ponen de manifiesto cómo un número importante de clérigos siguen presentando importantes lagunas en el ámbito de la cultura. Es verdad que en la Baja Edad Media se dio un paso importante en la elevación del nivel cultural del bajo clero, especialmente en el que desarrollaba su actividad en el ámbito urbano, mientras que los clérigos que vivían en las zonas rurales presentaban mayores deficiencias. En la diócesis de Jaén se denunciaba cómo determinadas personas incurrían en delito al mostrar falsos títulos que les otorgaban supuestos derechos para ocupar un beneficio vacante, usando como aliado en su engaño el que los clérigos y notarios a los que presentaban sus bulas no «saben ni entienden latín» 6 .

Este mismo temor de que personas no preparadas puedan hacerse cargo, aunque sea de forma temporal, de algunas parroquias por la ausencia de los priores o de los clérigos que gozan de cura de ánimas, hace que se establezca que cuando estos tengan que ausentarse por motivo justificado, y contando con la licencia del obispo o de su provisor, han de dejar a un capellán que esté

6 Rodríguez Molina, J., Sínodo de Jaén de 1492, Jaén, 1981, Tíulo I, Capitulo XLIIII, p. 103.

$\mathrm{I}^{\text {er }}$ Congreso de Historia de la Iglesia Hispania Sacra 51 (1999) 
preparado para hacerse cargo de sus tareas, conocimiento que deberían de haber demostrado éstos ante el obispo o su provisor al ser examinados por ellos, haciendo especial hincapié en que debían de conocer perfectamente la lengua latina. Con igual insistencia se pronuncia el sínodo de 1511, matizando que éstos capellanes que sustituyen a los beneficiados ausentes, han de percibir lo que le corresponde por el servicio que prestan, y no menos, pues hay veces en que el titular llega a un acuerdo con el capellán, de manera que éste percibe un salario mínimo que apenas si le llega para mantenerse?

Por lo menos en teoría, hay una preocupación constante porque la elección de los miembros del cabildo recaiga sobre personas preparadas. Las dignidades, cuya designación compete al obispo, presuponen que éste tendrá siempre presente la necesidad de que estas personas, que van a ocupar la jerarquía eclesiástica formando parte del escalafón más elevado y que van a gozar de los beneficios más sustanciosos, tenían que ser personas de vida honesta y de nivel cultural alto, pues lo contrario supondría uń fraude al servicio de Dios, que es el deber máximo de todos ellos.

En cuanto a la elección de los canónigos, conforme se fuesen produciendo bajas entre ellos, por verse estos ascendidos en su escala personal al grado de dignidades por ser promovidos a otras diocesis o por fallecimiento de los mismos, se expresa una preocupación constante porque presenten un nivel cultural optimo, o, por lo menos, ésta es la teoría. Insistimos en este punto porque, a lo largo de los estatutos y sínodos manejados pertenecientes a esta díocesis, se insiste mucho en el hecho de que con frecuencia se promociona a personas que no tienen la suficiente preparación y que por amiguismo, parentesco o por dinero se les coloca en puestos para los que no están preparados, siendo esta corruptela una de las faltas más graves que se pueden cometer.

De esta manera, tal y como se estipula en los estatutos y sínodos, la tercera canonjía que vacase y que le correspondía asignar al cabildo, ha de hacerlo al racionero más antiguo, salvo que hubiese otro que, aunque no fuese tan antjguo, estuviese más preparado y fuese «más ydóneo en çiençia, órdenes e costunbres» ${ }^{8}$, norma que se ha de respetar a la hora de ocupar la ración que queda vacante por promoción de un racionero a canónigo, condición que también se mantendrá vigente para el medio racionero que acceda a la ración vacante y al

7 Ibidem, Título I, Cap. XXVI, pp. 81 - 84; Sínodo de 1511, Archivo de la catedral de Jaén, Título П, Cap. III, fol. XVII r - XVUI v.

8 Rodríguez MOLINA, J., Estatutos de la catedral de Jaén de 1368. Recopilacín de 1478, Jaén, 1976, Título 3, pp. 43; GARCíA PARDO, M., El cabildo de la catedral de Jaén. Organización y vida (siglos XIII-XVI), Tesis Doctoral inédita, Apéndice documental I; Estatutos de la catedral de Jaén de 1492, Título 3, pp. 33. A partir de aquí las citas referentes a los estatutos de la catedral de Jaén se harán mencionando sólo el año al que corresponden. 
capellán que ocupará esta última. Siempre concederá el cabildo el tercer beneficio vacante, mientras que los dos primeros los otorgará el obispo.

Ejemplo de esto lo tenemos en los estatutos, cuando afirman que debe ser una persona «más idónea en sciençia», es decir, «se entienda al que fuere graduado en alguna facultad, asi que el bachiller se prefiera al non bachiller y el liçenciado al bachiller aviendo servido e residido en la iglesia por tres años»9.

Atendiendo a estas consideraciones, y en consonancia con ellas, las personas que fuesen receptoras de las dichas provisiones debían de estar preparadas, sabiendo leer, cantar y construir bien. Es decir, deben reunir todas aquellas atribuciones que son necesarias para ejercer correctamente el ministerio eclesiástico, y que debían poner de manifiesto y usar de ellas en los diferentes actos litúrgicos en los que se veían implicados a diario.

Sin embargo, como las autoridades eclesiásticas no están abstraídas de la realidad diaria, más aún, ellos mismos a menudo caían en el error o falta de atribuir estas provisiones a personas que no reunían los requisitos deseados, hay un intento por corregir la situación, dejando recaer el problema en la persona que, a sabiendas de sus limitaciones, aceptaba la provisión o la hubiese aceptado con anterioridad, acudiéndose a un recurso, habitual ya en los estatutos manejados, que estipula la penalización sobre el infractor a través de un castigo de carácter temporal que recaía sobre la economía particular de cada uno, medida que infundía más temor que las penas de carácter espiritual. Además, se contemplaba que los que hubiesen recibido beneficios en estas condiciones perderían la mitad de las distribuciones cotidianas, pitanzas y aniversarios, hasta que recibiesen la correspondiente instrucción ${ }^{10}$. De igual modo, se penaría a la persona que otorgase algún beneficio a otra a sabiendas de que no era la persona correcta.

Estas faltas en la instrucción elemental necesaria para el rezo de las horas canónicas, así como en la lectura de la epístola y del evangelio, quedan recogidas en los estatutos, plasmadas en la vigilancia que todo el colectivo debe realizar de las dichas faltas, corrigiendo a la persona que se equivocase en cualquiera de éstas, y debiendo dejar que acabe de pronunciarse el acto, y, después, de forma pausada y sin escándalo, corregir al equivocado para que no vuelva a caer en el error cometido.

9 Esta puntualización o aclaración se introduce en los estatutos de 1478 y se repetirán en los de 1492. Estatutos de la catedral de Jaén de 1368. Recopilación de 1478, Tínlo 3, p. 43; Estatutos de la catedral de Jaén de 1492, Título 3, pp. 33.

10 Estatutos de la catedral de Jaén de 1368. Recopilación de 1478, Título 3, p. 44; Estatutos de la catedral de Jaén de 1492, Título 3, p. 33.

$I^{\text {er }}$ Congreso de Historia de la Iglesia

Hispania Sacra 51 (1999) 
Pero no sólo los asistentes tienen la obligación moral de corregir al ignorante, sino que el cabildo, como institución, ya prevé la existencia de una persona que ha de velar por el correcto cumplimiento del oficio divino, cuidando y corrigiendo a los que lean y canten mal, mostrándoles como es la forma correcta de hacerlo. El peso de esta obligación recae en el chantre, como responsable máximo del correcto desarrollo del servicio en el coro y en el altar ${ }^{11}$.

Si el chantre debe ocuparse del cuidado de las faltas que se pudiesen cometer en el desarrollo de los oficios divinos por ignorancia de los asistentes, por dejadez, por falta de atención al estar ocupados en asuntos particulares que nada tienen que ver con el oficio que se está celebrando, etc., el maestrescuela sí que tiene la obligación de velar por el nivel cultural de los miembros del cabildo.

\section{El MAESTRESCUELA}

En la diócesis de Jaén la preocupación por la enseñanza y la preparación de las personas que forman parte del coro se pone ya de manifiesto en el primer ordenamiento que hizo don Fray Domingo, primer obispo de la sede, para la iglesia de Baeza. En él se establece que una persona, concretamente don Pascual de Segovia, que aparece como servidor, tenía la obligación de ocuparse, durante un tiempo, de la enseñanza de los niños que en esos primeros momentos formaran parte del coro, asignándosele cinco denarios de paga, a los que se le añadían siete denarios más durante el tiempo que se dedicase a la instrucción de los nin̄os ${ }^{12}$.

Conforme el cabildo giennense va adquiriendo mayor peso y sus funciones se van complicando, necesitando y pudiendo mantener a un mayor número de personas que se ocupen de determinadas tareas, van surgiendo las dignidades y entre ellas el maestrescuela. Su existencia aparece ya constatada en 1275 , aunque como ocurre en otras diócesis, éste terminará por convertirse en un cargo meramente honorífico, ya que parece que nunca se ocupó de impartir la enseñanza directamente, sino que su relación con esta actividad estaba en función de la búsqueda de una persona que se encargase de la misma, junto a la intervención en la selección de las personas que iban a acceder a ella.

11 Estatutos de la catedral de Jaén de 1368. Recopilación de 1478, Título 13, p. 98; Estatutos de la catedral de Jaén de 1492, Título 13, p. 95.

12 MARTINEZ DE MAZAS, J., Retrato al natural de la ciudad y termino de Jaen, Barcelona, 1978, apéndice documental sin numerar. Primer ordenamiento de la iglesia de Baeza realizado por el obispo don Domingo. 
El profesor Sánchez Herrero afirma que esta dignidad desempeñaba el cargo de canciller del cabildo, y que era el jefe del estudio ${ }^{13}$. Su función iba íntimamente ligada a la corrección y vigilancia del buen uso del lenguaje y de la lectura de los clérigos, especialmente de los miembros del cabildo, que tenían que adoctrinar con su ejemplo al resto de la masa clerical. También debía de proveer una persona idónea que se encargara tanto de enseñar a los niños del coro como de instruir a los clérigos.

Sus funciones concretas quedan plasmadas perfectamente en los estatutos de la catedral ${ }^{14}$, como ocurre con otras dignidades. Lógicamente, lo primero que se le exige es la vigilancia y control de los libros usados en la catedral para la realización del oficio divíno, que sean correctos y no haya ninguna falta en ellos, puesto que son la «herramienta de trabajo» a la que acuden los clérigos. Además, tiene que, actuando de forma conjunta con aquellos que lo van a realizar, es decir, con el diácono y subdiácono, informarles de la manera que han de leer la epístola y el evangélio. Tiene que corregir al resto de personas, en el coro y en el altar, para que la pronunciación y la lectura sean las correctas.

Le corresponde, además, guardar junto con el deán las llaves del arca, que se custodia en el vestuario, donde se encierra el sello del cabildo, necesario para dar certeza y validez a todos los documentos emanados del mismo, y por lo tanto, objeto bastante delicado. A él se encarga también que ponga un escribano fiable para que realice las cartas y dé fe de los acuerdos secretos del cabildo.

Hemos dejado para el final una de las tareas más delicadas del maestrescuela, que es la de designar un maestro de gramática y comprometerse a que si a éste le pasaba algo, él se encargaría de buscar un sustituto.

En realidad, esta dignidad no se ocupa de la instrucción de los clérigos, como podría parecer por su nombre, sino que lo que hace es controlar los aspectos relacionados con la educación, de la que en último término es responsable. Las razones que mueven a esto quedan claras cuando se dice:

"Porque aya siempre en la dicha nuestra iglesia e obispado clérigos letrados e que sepan latín, porque entiendan los ofiçios que se fizieren, $e$ por la çiençia sean alumbradas sus almas e las iglesias que se sirvieren, porque el derecho asi lo manda, ... sea tenudo de poner un maestro idóneo e sufç̧iente que tenga escuela de gramática en la muy noble çibdad de Jahén".

Todas estas obligaciones conllevan que esta dignidad tenga que hacer frente a grandes gastos derivados de su oficio, por lo que se ve la necesidad de

13 SÁNCHEZ HERRERO, J., Las diócesis del reino de León (siglos XIV y XV), León, 1978, p. 99.

14 Estatutos de la catedral de Jaén de 1368. Recopilación de 1478, Título 14, pp. 99 - 101; Estatutos de la catedral de Jaén de 1492, Título 14, pp. 96- 97.

$I^{\text {er }}$ Congreso de Historia de la Iglesia

Hispania Sacra 51 (1999) 
proveerlo de altos ingresos. Así, además de la ración que le corresponde en calidad de su categoría de dignidad, se le añaden seiscientos maravedís de la mesa capitular, sumándole además todos «los terçuelos de las iglesias de todas las çibdades e villas e lugares e castillos $e$ aldeas de todo este obispado. E de todos los otros lugares que fazen rentas por sí, de cada uno de los dichos terçuelos una fanega de trigo e otra de çebada cada año, segund que de costumbre antigua le suele llevans.

Si faltase en el cumplimiento de sus obligaciones, se le penará con que no gane el dicho pan contándolo por prorrata, y si ya lo ha cobrado, se le descontará de su ración, pena que debe ser controlada tanto por el cabildo como por los contadores, encargándose el obispo, o su vicario en ausencia de éste, junto con el cabildo, de poner maestro a costa del dicho maestrescuela.

Conocemos el caso de Juan de Granda que, en el año 1443, aparece como bachiller en decretos, profesor de gramática en Salamanca y catedrático de gramática y de artes en la iglesia de Jaén ${ }^{15}$.

Del mismo modo se establece que este bachiller en decretos por Salamanca es invitado por el cabildo gienense para hacerse cargo de la enseñanza de la gramática y de la dialéctica en la iglesia de Jaén, según queda constancia en la súplica fechada el día 13 de abril de $1443^{16}$.

Con esta misma fecha, a instancias del infante de Castilla don Enrique y del obispo y cabildo de Jaén, se le confiere un canonicato en esta iglesia al dicho Juan de Granda, resaltándose el hecho de que durante diez años había enseñado gramática y dialéctica en Salamanca y otras partes ${ }^{17}$.

Como vemos, la iniciativa parte del cabildo, con su obispo a la cabeza.

No obstante, dentro de las atribuciones del maestrescuala hay una relacion directa con la escuela de gramática, asignándosele a él la capacidad de aconsejar qué personas de los colegios y universidades de Jaén y Baeza deben de acudir a aprender gramática en la ciudad de Jaén, contando con el consejo del vicario general o de dos personas o canónigos de la iglesia, o del arcipreste o abad de cada uno de los arciprestazgos. Respecto a los de las otras universidades o arciprestazgos, deberán ser elegidos por el maestrescuela con el consejo de los arciprestes o abad de la universidad si existe, y si no, con el del arcipreste o vicario o de dos priores o beneficiados de los más antiguos del arciprestazgo. La elección debe de hacerse sin que influyan lazos de parentesco o

15 Beltrán DE HeRedia, V., Bulario de la Universidad de Salamanca (1219 - 1549), Tomo I, Universidad de Salamanca, 1966, p. 165.

16 Ibidem, p. 209.

17 BELTRÁN DE HEREDIA, V., Bulario de la Universidad de Salamanca (1219 - 1549), Tomo II, Universidad de Salamanca, pp. $508-609$. 
de simpatía o a cambio de una paga. Los seleccionados gozarán de esta situación de privilegio por tres años, y sólo pueden ser cambiados por la muerte de alguno de los elegidos o por que no se empleen a fondo en su estudio, lo cual tendría que venir avalado por el maestro de gramática bajo juramento, eligiendo entonces el maestrescuela un nuevo estudiante que ocuparía el lugar dejado. Sólo por causas justificadas se podrían ausentar los estudiantes, pero tendrían que obtener un alvalá del maestrescuela o de su lugarteniente, juntamente con el maestro de gramática' ${ }^{18}$.

\section{LA ESCUELA DE GRAMÁTICA}

Como ya hemos dicho anteriormente, la elección del maestro de gramática corresponde al mestrescuela, encargándose este de la primera enseñanza, y en caso de que tuviese que marcharse, por fallecimiento o por cualquier otro motivo, esta dignidad sería la que debería proporcionar un sustituto adecuado al mismo, de forma que si falta a su oficio puede el cabildo buscar un maestro, cargando todos los gastos que pudieran generarse sobre el maestrescuela (tal y como vimos anteriormente).

Los requisitos que deben presentar los aspirantes a ocupar la cabeza de esta escuela, es decir, el maestro que se haga cargo de ella, también aparecen recogidos en los estatutos, y marcan la elección que debe realizar la dignidad en base a ellos:

- Su preparación ha de ser la correcta.

- Que lea correctamente.

- Que esté dispuesto a emplearse a fondo y diligentemente en la enseñanza de los escolares, apremiándolos e instándolos, para que aprendan en el menor tiempo posible y con la mayor profundidad que puedan alcanzar.

- Que se comprometan a llevar a buen término el cumplimiento del calendario escolar, que va desde el día de San Lucas hasta el día de Santa María Magdalena.

El sueldo que se establece para el mantenimiento del maestro de gramática es de quinientos maravedís cada año, que le serán pagados de la Obra de la iglesia catedral, estipulándose además que cada uno de los que acudan a sus clases le pague doscientos maravedís, y que él se ponga de acuerdo en la can-

\footnotetext{
18 Cuando en este trabajo se habla de universidades se refiere al conjunto de clérigos de un lugar determinado que se unen para defender sus derechos, y no a lo que hoy entendemos por universidad.

$I^{\text {er }}$ Congreso de Historia de la lglesia

Hispania Sacra 51 (1999)
} 
tidad que tendrán que aportar los otros estudiantes, excepto los pobres, a los que no debe de cobrar nada. Estos estudiantes pobres, con los que la iglesia tiene una cierta deferencia, tendrían que mantenerse con las limosnas aportadas por los parroquianos, pues éstos serían asignados a los priores de ciertas colaciones o aldeas, a los que presentarían un alvalá del maestrescuela, y éstos se encargarían de inducir al pueblo para que les dieran las limosnas que necesitaban para asistir a la escuela. Debido a la comupción presente en todos los ámbitos de la jerarquía eclesiástica, se prevé que el maestrescuela no vaya, bajo pena de excomunión, a cobrar nada por hacer el alvalá necesario, y se sobrentiende que tampoco debe falsificar el estado económico real de los estudiantes. Estas prohibiciones no hacen más que confirmar que estos «malos usos» se producían con cierta frecuencia.

Para que todos los arciprestazgos que conforman el obispado de Jaén puedan gozar de algún beneficiado estudiante, evitando que estos puestos fuesen copados por aquellos beneficiados pertenecientes a los más fuertes o con mayor influencia, en los estatutos se establece de forma clara y contundente cómo y de dónde han de provenir los diferentes estudiantes ${ }^{19}$ :

- De la iglesia catedral de Jaén y Baeza, tres beneficiados, que serían designados por el deán y cabildo.

- De la ciudad de Jaén y de su arciprestazgo, cuatro escolares beneficiados.

- De Arjona y su arciprestazgo, uno.

- De Baeza y su arciprestazgo, cuatro.

- De Andújar y su arciprestazgo, uno.

- De Úbeda y su arciprestazgo, uno.

- De Santisteban del Puerto y de su arciprestazgo, uno.

- De Iznatoraf y su arciprestazgo, uno.

Sin embargo, a la vista de estos datos podemos observar como hay grandes diferencias entre unas zonas y otras, de forma que se van a promocionar más los de determinados sectores de la clerecía, quizás también en consonancia con la necesidad que en estas partes se da de contar con unos clérigos más preparados debido a la importancia de las iglesias de las que son beneficiados y al mayor número de fieles y de clérigos, ya que son zonas más pobladas. Parece claro que Jaén y Baeza ocupan un lugar destacado, concentrándose en estas zonas el mayor número de beneficiados estudiantes, tres pertenecientes a las dos catedrales y ocho en total para el resto de la clerecía de ambas zonas. Este

19 RodrtGuez Molina, J., El obispado de Baeza-Jaén. Organización y economía diocesanas (siglos XIII - XVI), Jaén, 1986, p. 126. 
mayor número viene marcado por su consideración de núcleos importantes de población, en los que se ha de tener un especial cuidado en las labores del culto, así como por ser zonas más pudientes, que pueden mantener, con más comodidad, mayor número de estudiantes.

El resto de los arciprestazgos aparecen igualados, salvo la excepción de Úbeda. Tampoco nos extraña este dato, pues esta ciudad constituía otro de los núcleos importantes de la diócesis de Jaén, y gozaba además, al igual que Baeza, de una colegiata, y por tanto tenía un gran peso dentro del obispado.

En principio, estos beneficiados así elegidos han de permanecer en estudio durante tres años, sin poder ausentarse, aplicándose de lleno en sus obligaciones escolares. Si respetan estas condiciones no podrán ser cambiados de manera caprichosa, como ya apuntamos con anterioridad, por parte del maestrescuela o de cualquier otro oficial relacionado con ellos. Tan sólo se contempla la posibilidad de que puedan dejar el estudio, es decir, ausentarse durante un período de tiempo, cuando tengan un motivo muy justificado, pudiendo contar entonces con la licencia debida por parte del maestrescuela o consentida por el maestro que se ocupa de su instrucción. Este único motivo consiste en la muerte o enfermedad grave de sus padres o de algún otro familiar muy cercano. El tiempo que puede durar esta licencia será determinado por el maestrescuela o por el maestro de gramática, y el estudiante tiene que comprometerse a que, finalizado el mismo, se reincorporará al estudio, jurando ante el maestrescuela que la causa que alega para su ausencia es cierta y no encierra ninguna malicia ni engaño.

Del mismo modo queda contemplado que aquellos que se ausenten sin licencia o con engaño pierdan los frutos que les corresponden por todo el año de su beneficio. En contrapartida, aquellos que se aplican en su estudio y están presentes en él sin acarrear ningún problema, han de percibir todas aquellas cosas que les corresponden, como son:

\footnotetext{
«... todas las rentas de sus benefiçios asi del pontifical e pan e vino e azeite, como, asimismo, el pie de altar por lo qual se entiende el diezmo de las ortalizas e maravedís de çenso. E han más de aver sus partes de las possesiones de las iglesias donde fueren benefiçiados los tales estudiantes e de la premicias» 20 .
}

Tan sólo se contempla una excepción con respecto a lo que le corresponde ganar a cualquier beneficiado que se encuentre presente en su beneficio, como es lo que se solía ganar con la asistencia a los oficios de difuntos, así como en la parte que les correspondía de la ofrenda (en ellas realizada) de vino, trigo,

20 Estatutos de la catedral de Jaén de 1368. Recopilación de 1478, Título 15, pp. 104 - 105; Estatutos de la catedral de Jaén de 1492, Título 15, p. 102.

$\mathrm{I}^{\mathrm{er}}$ Congreso de Historia de la Iglesia

Hispania Sacra 51 (1999) 
dineros, obladas, cera u otra ofrenda que se solía acompañar a la celebración del enterramiento. Es decir, solo ganarían estas cosas siempre que se encontrasen presentes en los oficios o misas de difuntos.

Otro privilegio que se les concede a los beneficiados estudiantes es el que se encuentren exentos, durante los tres años que han de ocuparse de sus estudios, de pagar la Procuración y el Catedrático, además de cualquier otro pago ordinario o extraordinario que pudiese presentarse, tanto real como episcopal, dejándose claro que la parte que les corresponde pagar había de ser repartida entre el resto de los clérigos del arciprestazgo al que pertenezca el beneficiado estudiante durante los tres años que está en estudio, pagando entre todos por él.

La iglesia de Jaén contempla la posibilidad de que, además de la escuela de gramática dependiente del cabildo, se puedan instaurar en Jaén o en cualquier otra población de la diócesis escuelas creadas por laicos o dependientes de una institución laica, a las que pudiesen asistir nin̄os. Lo que ocurre es que la sensación que trasmiten los documentos con los que contamos hasta el momento es que en principio en estas escuelas se han de enseñar, también, los principios de la doctrina cristiana, junto con, parece lógico pensar, las nociones necesarias para completar una enseñanza mínima. Lo único que se recomienda, por parte de la iglesia, es que estas escuelas se sitúen proximas a alguna iglesia, para que los estudiantes puedan acudir a escuchar los oficios divinos.

Un ejemplo de una de estas escuelas lo tenemos en 1470, y nos ha sido trasmitido a través de la crónica del Condestable don Miguel Lucas de Iranzo. En ella se recoge, como testimonio de la benevolencia y entrega de éste personaje, al que a través de esta crónica, lógicamente, se quiere ensalzar, el siguiente pasaje y testimonio:

"Y dexando esto aparte, como en todas cosas se exerçitase la virtud y grandeza de su coraçón, como quiera que a lo siguiente el obispo y deán y cabildo eran más obligados, en defecto suyo, embió a Seuilla por vn buen maestro de gramática, e mandóle asentar escuela en la çibdad de Jahén, e salario de dineros e pan de lo suyo; para que a todas e qualesquier personas del obispado de Jahén que quisieren aprender les abezasa gramática y retórica y lógica, y todas las artes liberales, sin les leuar salario ni presçio ninguno, ca él ge lo pagaua por todos»21.

Como vemos en este pasaje, el cronista pone de manifiesto la dejadez que, tanto el obispo como el cabildo, hacen de sus funciones, no cumpliendo con su obligación de proporcionar un maestro idóneo. Aunque no hay que perder de vista el enfrentamiento constante que, a todo lo largo de la crónica, se pone de

21 CARriazo, J M., Hechos del Condestable Don Miguel Lucas de Iranzo, (Crónica del siglo $X V)$, Madrid, 1940, p. 453. 
manifiesto entre el obispo y el condestable, por lo que esta noticia y lo que para nosotros puede significar como de falta de cumplimiento por parte del cabildo de una función que, no obstante, aparece como muy importante en los estatutos, puede presentar algo de manipulación y exageración por parte del autor para ensalzar la figura de don Miguel Lucas de Iranzo y lanzar una serie de sombras sobre el escalafón más elevado de las dignidades eclesiásticas, con el que existen ciertos enfrentamientos.

En conclusión, los datos hasta ahora manejados parecen poner de manifiesto la existencia de vacíos, de una mala preparación de los clérigos en aquellos conocimientos que les eran más necesarios para afrontar y ejercer sus tareas cultuales, en gran medida favorecida esta situación por permitirse con frecuencia el acceso a beneficios vacantes de amigos y parientes que no están preparados para ello así como por la existencia de numerosos clérigos asalariados, que vivían en condiciones muy precarias. 